\title{
Plastic-Degrading Potential across the Global Microbiome Correlates with Recent Pollution Trends
}

\author{
(D) Jan Zrimec, ${ }^{\text {a,b }}$ Mariia Kokina, ${ }^{\text {a,c }}$ Sara Jonasson, ${ }^{\text {a }}$ Francisco Zorrilla, ${ }^{a, d}$ (D) Aleksej Zelezniak ${ }^{a, e}$ \\ aDepartment of Biology and Biological Engineering, Chalmers University of Technology, Gothenburg, Sweden \\ bDepartment of Biotechnology and Systems Biology, National Institute of Biology, Ljubljana, Slovenia \\ cNovo Nordisk Foundation Center for Biosustainability, Technical University of Denmark, Kongens Lyngby, Denmark \\ dMRC Toxicology Unit, Cambridge, United Kingdom \\ eInstitute of Biotechnology, Life Sciences Center, Vilnius University, Vilnius, Lithuania
}

ABSTRACT Biodegradation is a plausible route toward sustainable management of the millions of tons of plastic waste that have accumulated in terrestrial and marine environments. However, the global diversity of plastic-degrading enzymes remains poorly understood. Taking advantage of global environmental DNA sampling projects, here we constructed hidden Markov models from experimentally verified enzymes and mined ocean and soil metagenomes to assess the global potential of microorganisms to degrade plastics. By controlling for false positives using gut microbiome data, we compiled a catalogue of over 30,000 nonredundant enzyme homologues with the potential to degrade 10 different plastic types. While differences between the ocean and soil microbiomes likely reflect the base compositions of these environments, we find that ocean enzyme abundance increases with depth as a response to plastic pollution and not merely taxonomic composition. By obtaining further pollution measurements, we observed that the abundance of the uncovered enzymes in both ocean and soil habitats significantly correlates with marine and country-specific plastic pollution trends. Our study thus uncovers the earth microbiome's potential to degrade plastics, providing evidence of a measurable effect of plastic pollution on the global microbial ecology as well as a useful resource for further applied research.

IMPORTANCE Utilization of synthetic biology approaches to enhance current plastic degradation processes is of crucial importance, as natural plastic degradation processes are very slow. For instance, the predicted lifetime of a polyethylene terephthalate (PET) bottle under ambient conditions ranges from 16 to 48 years. Moreover, although there is still unexplored diversity in microbial communities, synergistic degradation of plastics by microorganisms holds great potential to revolutionize the management of global plastic waste. To this end, the methods and data on novel plastic-degrading enzymes presented here can help researchers by (i) providing further information about the taxonomic diversity of such enzymes as well as understanding of the mechanisms and steps involved in the biological breakdown of plastics, (ii) pointing toward the areas with increased availability of novel enzymes, and (iii) giving a basis for further application in industrial plastic waste biodegradation. Importantly, our findings provide evidence of a measurable effect of plastic pollution on the global microbial ecology.

KEYWORDS bioinformatics, environmental microbiology, metagenomics, microbial ecology, plastic pollution

\footnotetext{
- he demands for plastic production are increasing annually despite plastic waste pollution presenting a major global environmental problem. The majority of plastic products end up in landfills or dispersed in the environment (1), with inadequate waste
} 
management leading to an estimated 9 to 14 million metric tons of plastic entering the ocean every year (2) on top of the already accumulated $\sim 150$ million metric tons (3). Even plastic additives such as phthalate compounds, frequently used as plasticizers, are a major source of concern due to their overuse in a variety of different products and adverse health effects $(4,5)$. While some thermoplastics (polyethylene [PE], polypropylene [PP], polyethylene terephthalate [PET], polyvinyl chloride [PVC], and phthalic acid [PA]) can be recycled, contaminated and composite plastics as well as thermosets (polyurethane [PU] and vinyl esters) cannot be remolded or heated after the initial forming $(6,7)$. Although the durability of man-made synthetic plastics facilitates their persistence in the environment, the synthetic polymers, like natural polymers (e.g., polysaccharides), can serve as a microbial carbon source (8-10). Microorganisms thus mediate a number of plastic biodegradation reactions across different environments (11-16), and even plastics such as PET (10) and PU (17) can be transformed and metabolized by microbial species. However, despite this widespread degradation capability, the true microbial potential for plastic degradation across different global habitats is not yet fully understood.

The isolation, identification, and characterization of microorganisms with plasticdegrading potential are frequently conducted from aquatic environments (18-21), waste disposal landfills (22-25), or places that are in direct contact with the plastic, such as plastic refineries (26-28). However, growing microorganisms outside their natural environments using conventional approaches is extremely challenging (29) and limits the amount of isolated species that can be cultured and studied to as little as $1 \%$ or lower (30). Studying single microbial isolates also limits our understanding of the microbial ecology of plastic degradation, where microbial consortia have been found to act synergistically, producing more enzymes and degrading plastics more efficiently than individual species $(31,32)$. Likewise, localized analyses from single locations hinder our understanding of the global environmental impact of plastic materials (33). On the other hand, with advances in environmental DNA sequencing and computational algorithms, metagenomic approaches enable the study of the taxonomic diversity and identification of the functional genetic potential of microbial communities in their natural habitats (33-35). For example, global ocean sampling revealed over 40 million mostly novel nonredundant genes from 35,000 species (35), whereas over $99 \%$ of the $\sim 160$ million genes identified in global topsoil cannot be found in any previous microbial gene catalogue (34). This indicates that global microbiomes carry an enormous unexplored functional potential, with unculturable organisms as a source of many novel enzymes (30). Identification of such enzymes involved in the biological breakdown of plastics is an important first step toward a sustainable solution for plastic waste utilization $(36,37)$. However, despite the availability of experimentally determined protein sequence data on plastic-degrading enzymes (10, 38-43), no large-scale global analysis of the microbial plastic-degrading potential has yet been performed.

In the present study, we explored the global potential of microorganisms to degrade plastics. We compiled a data set of all known plastic-degrading enzymes with sequence-based experimental evidence and construct a library of hidden Markov models (HMMs), which we used to mine global metagenomic data sets covering a diverse collection of oceans, seas, and soil habitats $(34,35,44,45)$. By controlling for false positives using gut microbiome data (46), we compiled a catalogue of over 30,000 nonredundant enzyme homologues with the potential to degrade 10 different plastic types. Comparison of the ocean and soil fractions shows that the uncovered enzymatic potential likely reflects the major differences related to the composition of these two environments. Further analysis of metagenome-assembled genomes in the ocean reveals a significant enrichment of plastic-degrading enzymes within members of the classes Alphaproteobacteria and Gammaproteobacteria and supports the notion that enzyme abundance increases with sea depth as a response to plastic pollution and not merely taxonomic composition (47-50). By relating the identified enzymes to the respective habitats and measured environmental variables within the soil and ocean 
A

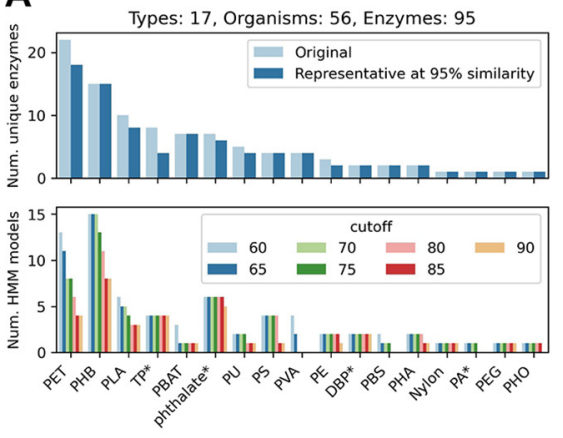

B

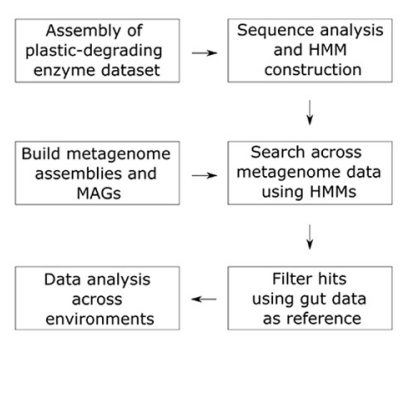

C

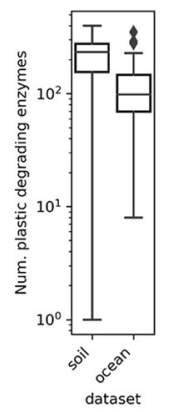

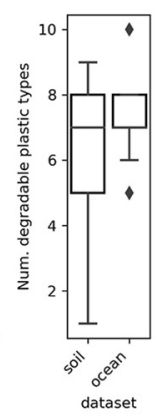

D

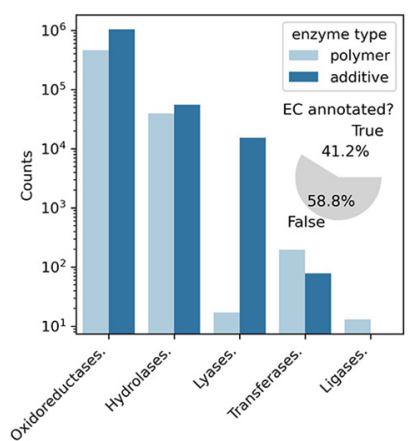

FIG 1 Global microbiome harbors thousands of potential plastic-degrading enzymes. (A) Compiled enzyme data set and representative sequences obtained by clustering (95\% sequence identity cutoff), covering the major types of pollutant plastics (PVA, polyvinyl alcohol; PLA, polylactic acid; PU, polyurethane; PHB, polyhydroxybutyrate; PBS, polybutylene succinate; PET, polyethylene terephthalate; PBAT, polybutylene adipate terephthalate; PE, polyethylene; PEG, polyethylene glycol; PHO, poly(3-hydroxyoctanoate)) and additives/plasticizers (phthalate; PA, phthalic acid; DBP, di- $n$-butyl phthalate; TP, terephthalic acid). The lower plot shows the final constructed HMMs across the different sequence identity cutoffs. (B) Schematic overview of the implemented and applied procedures in this study. (C) Number of plastic-degrading enzyme hits and degradable plastic types across the ocean and soil microbiome fractions. (D) Enzyme classes (EC) predicted with orthologous function mapping (66) at the topmost EC level. (Inset) Number of EC annotated results.

environments, we further showed that the abundance of the uncovered enzymes significantly correlates with both marine and country-specific plastic pollution measurements (51-56), suggesting that the earth's microbiome might already be adapting to current global plastic pollution trends.

\section{RESULTS}

The global microbiome harbors thousands of potential plastic-degrading enzymes. To probe the potential for plastic degradation across the global microbiome, we compiled a data set of known enzymes with experimental evidence of plastic-modifying or -degrading activity from published studies (10, 38-42, 57-62) and databases (43), including a total of 95 sequenced plastic enzymes spanning 17 different plastic or additive types from 56 distinct microbial species (Fig. 1A; also, see "Enzyme data set and construction of HMMs" in Materials and Methods). The types of plastics (13 types) and plastic additives (4 types of phthalate-based compounds) (Fig. 1A; additives are marked with asterisks) spanned the main types of globally produced plastics that constitute the major fraction of global plastic waste (1), except for PP and PVC, for which no representatives could be found (Fig. S1A). To enable efficient searching across global metagenomic data sets, we built HMMs (63) by including the known homologous sequences from the UniProt TrEMBL database (64) (Fig. 1B; Fig. S1B and C). Briefly, we clustered the known enzymes to obtain representative sequences (95\% sequence identity) (Fig. 1A) and used these to query the UniProt TrEMBL database and obtain an expanded data set of a total of 16,834 homologous enzyme sequences ( $E$-value $<1 \mathrm{e}-10$ ) (Fig. S1C). Each group of enzyme sequences at a given BLAST sequence identity cutoff ranging from $60 \%$ (65) to $90 \%$ was then clustered ( $95 \%$ sequence identity) to obtain groups of representative sequences that were used to construct a total of 1,201 HMMs (Fig. 1A; Fig. S1; see "Enzyme data set and construction of HMMs" in Materials and Methods).

The HMMs were then used to search for homologous sequences from the metagenomes spanning 236 sampling locations (see "HMM queries across metagenomes and data filtering" in Materials and Methods; Fig. 2) that included global ocean (35), global topsoil (34), and additional Australian (45) and Chinese (44) topsoil projects (see "Metagenome assemblies and MAGs" in Materials and Methods; Table 1). With over $73 \%$ of orthologous groups shared between gut and ocean microbiomes (35), a high number of false-positive identifications would be expected, as certain enzymes might have related evolutionary ancestry but no plastic degradation activity. Thus, as a control, we filtered the environmental hits by comparing them to those in the gut 


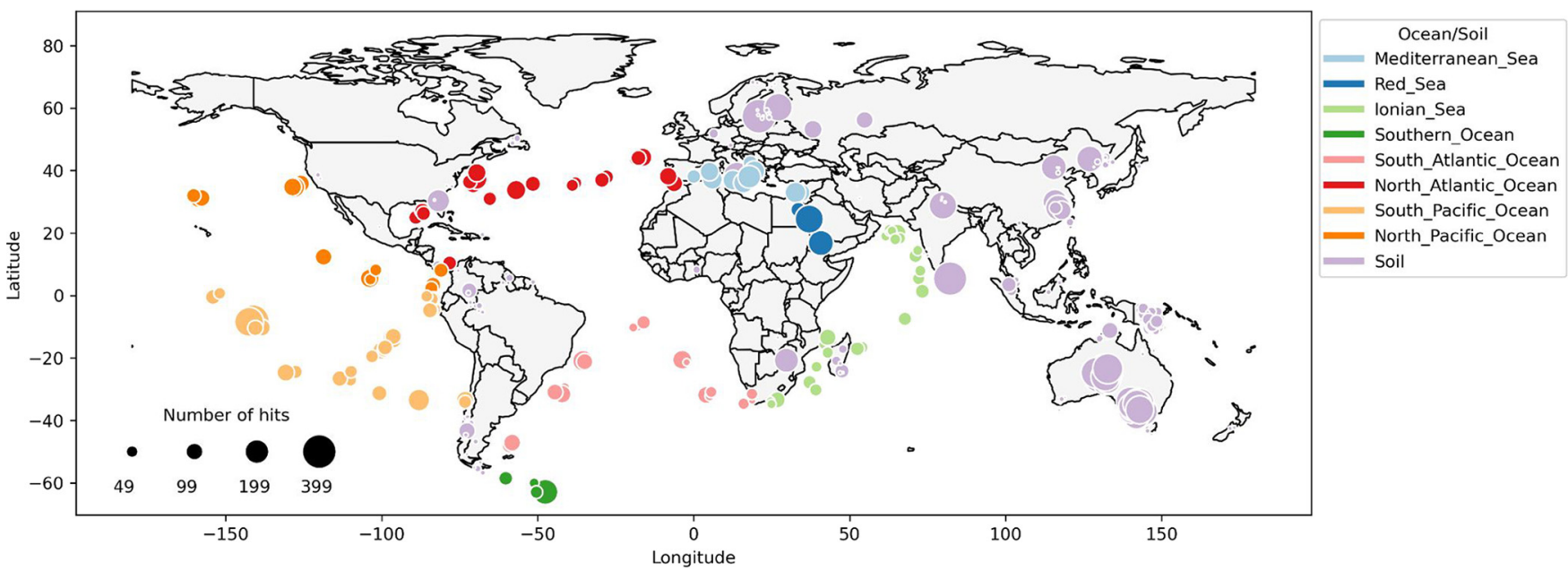

FIG 2 Plastic-degrading enzymes across the global microbiome. Depicted are 11,906 enzyme hits in the ocean and 18,119 in the soil data sets, obtained by constructing HMMs of known plastic-degrading enzymes and querying them across metagenomic sequencing data sets. The potential to degrade up to 10 and 9 different plastic types was observed in the respective ocean and soil fractions (Fig. S3A).

microbiome (46), where, to our knowledge, no plastic-degrading species have yet been found. Briefly, for each HMM, precision and recall were computed by comparing the corresponding hits in the global microbiomes to those in the gut microbiome; to minimize the risk of false positives, models with hits in the global microbiomes with scores above a precision threshold of $99.99 \%$ and an area under the precision-recall curve (AUC) of $75 \%$ were retained (Fig. S2; see "HMM queries across metagenomes and data filtering" in Materials and Methods). The final filtered results with the global microbiomes contained 121 unique HMMs, of which 99 matched (E-value $<1 \mathrm{e}-16)$ ocean samples and 105 matched soil samples, representing $10 \%$ of the initial HMMs used prior to filtering (Table 1). Consequently, an average of 1 in 4 organisms in the analyzed global microbiome was found to carry a potential plastic-degrading enzyme (Table 1).

Altogether, we identified 11,906 enzyme homologues in the ocean and 18,119 in the soil data sets (Fig. 2). Referring to the total number of unique plastic types that can be degraded based on the identified hits, the recovery of the 17 unique plastic types was $\sim 60 \%, 10$ in the ocean and 9 in the soil data sets. Of these, 38 HMMs matched $43 \%$ of hits corresponding to the 6 plastic polymers (Fig. S3A) (polybutylene adipate terephthalate [PBAT], polyethylene glycol [PEG], PET, polyhydroxybutyrate [PHB], polylactic acid [PLA], and PU), and 83 HMMs identified $57 \%$ of hits corresponding to the 4 additives (Fig. S3A; di-n-butyl phthalate [DBP], PA, terephthalic acid [TP], phthalate). Specifically, of the plastic polymer enzyme hits, PU was found only in the ocean and not in the soil microbiome, whereas $>2$-fold-larger amounts of PEG, PBAT, and PHB and a 2-fold smaller amount of PET were found in the ocean fraction than the soil fraction (Fig. S3A). The number of hits corresponding to additives was significantly larger (Fisher's exact test one-tailed $p$-value $=5.4 \mathrm{e}-6$ ) in the soil fraction than the ocean

TABLE 1 Overview of the metagenomic data sets and results analyzed in the study ${ }^{a}$

\begin{tabular}{llllllllll}
\hline & No. of: & \multicolumn{1}{l}{} & & & & & \\
\cline { 2 - 8 } Data set & Genes & Samples & HMMs & Hits & Plastic types & Polymers & Additives & Hits per gene & Organisms per hit \\
\hline soil_Australia (45) & $78,849,927$ & 46 & 99 & 11,093 & 9 & 4,224 & 6,869 & $1.41 \mathrm{e}-04$ & 3.59 \\
soil_global (34) & $21,248,672$ & 261 & 84 & 6,175 & 9 & 1,098 & 5,077 & $2.91 \mathrm{e}-04$ & 1.74 \\
soil_China (44) & $6,536,825$ & 6 & 50 & 851 & 7 & 273 & 578 & $1.30 \mathrm{e}-04$ & 3.88 \\
ocean (35) & $107,735,703$ & 139 & 99 & 11,906 & 10 & 7,232 & 4,674 & $1.11 \mathrm{e}-04$ & 4.57 \\
$\quad$ Weighted avg & $53,592,782$ & 113 & 83 & 7,506 & 9 & 3,207 & 4,300 & $1.40 \mathrm{e}-04$ & 3.61 \\
$\quad$ Total & $214,371,127$ & 452 & 121 & 30,025 & 10 & 12,827 & 17,198 & & \\
\hline
\end{tabular}

a"Hits" and "plastic types" refer to the number of plastic-degrading enzyme hits and number of degradable plastic types, respectively; "polymers" and "additives" specify the amount of plastic polymer and additive-degrading hits, respectively. 
fraction, representing $69 \%$ of the total amount of soil hits compared to $39 \%$ in the ocean fraction and resulting in an almost 4-fold increase in the average number of additive-degrading hits across the soil sampling sites (Fig. S3B). On the other hand, the overall numbers of polymer-degrading hits across the samples were similar in both the soil and ocean fractions, with a $15 \%$ larger number observed in the soil samples (Fig. S3B). The resulting number of all hits, including polymers and additives was thus, on average, over 2-fold larger across the soil samples than in the ocean samples, whereas the numbers of distinct degradable plastic types were equal (Fig. 1C). These results were, however, much more variable across the soil fraction, where, for instance, the variability of the number of hits across soil sampling sites was over 4-fold greater than in the ocean fraction (Fig. 1C).

The identified enzyme hits were annotated using orthologous function mapping $(66,67)$ (see "Enzyme function and environmental data analysis" in Materials and Methods), which assigned EC enzyme classifications for $41 \%$ of the hits (Fig. 1D, inset), with the majority of the annotated enzyme classes corresponding to oxidoreductases, hydrolases, and lyases (Fig. 1D). An over-2-fold larger fraction of additive-degrading hits were annotated compared to the polymer-degrading hits, meaning that, whereas approximately one-half of all the additive-degrading hits were annotated, this was the case with only $29 \%$ of the polymer-degrading hits (Fig. S4A). Despite similarities in distributions of the general classes across the ocean and soil fractions (Fig. 1D), 37\% fewer hits were annotated with the soil fraction (Fig. S4B). Further analysis showed that, indeed, differences in function were present, with the ocean fraction possessing an $11 \%$ larger diversity of enzyme functions than soil (Fig. S4D: 40 versus 36 distinct enzyme types with at least 3 occurrences) and $27 \%$ of the enzyme functions differing among the two microbiome fractions. The difference between the additive and polymer-degrading hits was, however, already discernible at the level of general enzyme classes (Fig. S4C). Similarly, in both ocean and soil fractions, an almost 3-fold-larger amount of functional diversity was present with the additive-degrading hits than with the polymer-degrading hits, and only a single function (2\%) was shared among the additive- and polymer-degrading groups (Fig. S4E).

Earth microbiome's plastic-degrading potential might already be adapting to global pollution trends. The analyzed ocean microbiome spanned 67 locations sampled at 3 depth layers and across 8 oceans (Fig. 2; see "Enzyme function and environmental data analysis" in Materials and Methods). A significant (rank sum test $p$-value $<2.9 e-2$ ) increase of plastic-degrading enzyme hits was identified in samples obtained from the Mediterranean Sea and South Pacific Ocean compared to the other locations (Fig. 3A; Table S1), which might reflect the relatively high plastic pollution in these areas $(53,68)$. A larger amount of pollution in sampling areas in the lower longitudinal region, however, might be indicated by the significant negative correlation (Spearman $\rho=0.393$ and $0.357 ; p$-value $<1.6 \mathrm{e}-5$ ) of the numbers of both degradable plastic types and enzyme hits, respectively, with longitude (Fig. 3B; Fig. S5A). Whereas the majority of plastic polymer and additive types were found across all oceans, PU was present only in the Ionian Sea and South Pacific Ocean and PLA was present only in the Ionian Sea, likely reflecting their overall 6-fold-lower content than the other degradable plastic types (Fig. S6A).

As expected according to published results showing an increasing amount of taxonomic and functional richness with depth (35), we observed measurable depth stratification of the enzyme hits in the ocean samples (Fig. 3C; see "Enzyme function and environmental data analysis" in Materials and Methods). Both the amount of degradable plastic types and enzyme hits were positively correlated with depth (Spearman $\rho=0.552$ and 0.384 , respectively; $p$-value $<4.3 \mathrm{e}-6$ ) as well as negatively correlated with temperature (Spearman $\rho=$ 0.451 and 0.336 , respectively; $p$-value $<6.7 e-5$ ) (Fig. 3B and C; Fig. S5A). This was also supported by principal-coordinate analysis (PCOA) on enzyme hits across samples (see "Enzyme function and environmental data analysis" in Materials and Methods), where the first principal coordinate carrying $25 \%$ of the data variance correlated significantly (Spearman $\rho=$ 0.453 and $-0.420 ; p$-value $<4 \mathrm{e}-7$ ) with both depth and temperature, respectively 
A
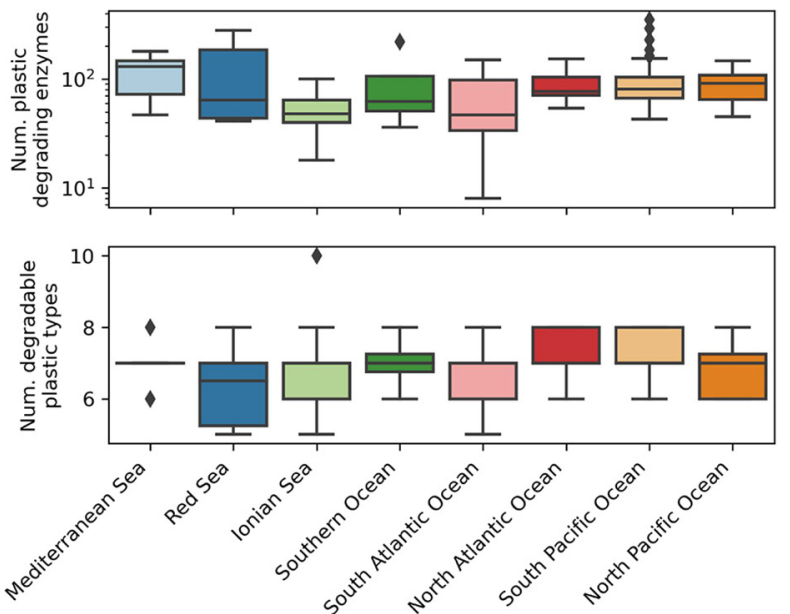

D
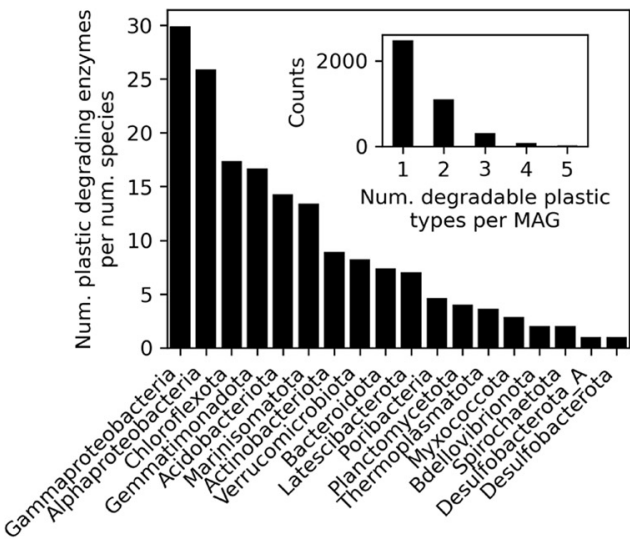

B

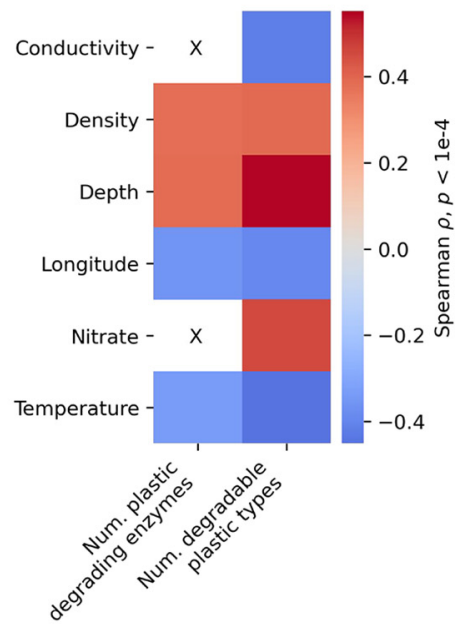

C

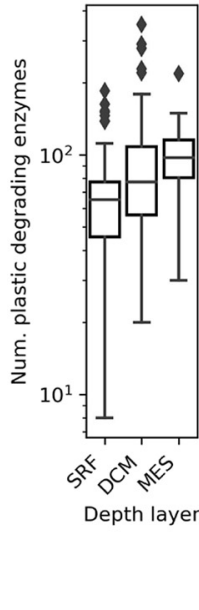

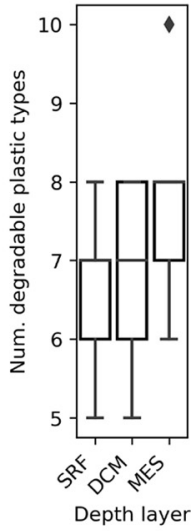

E

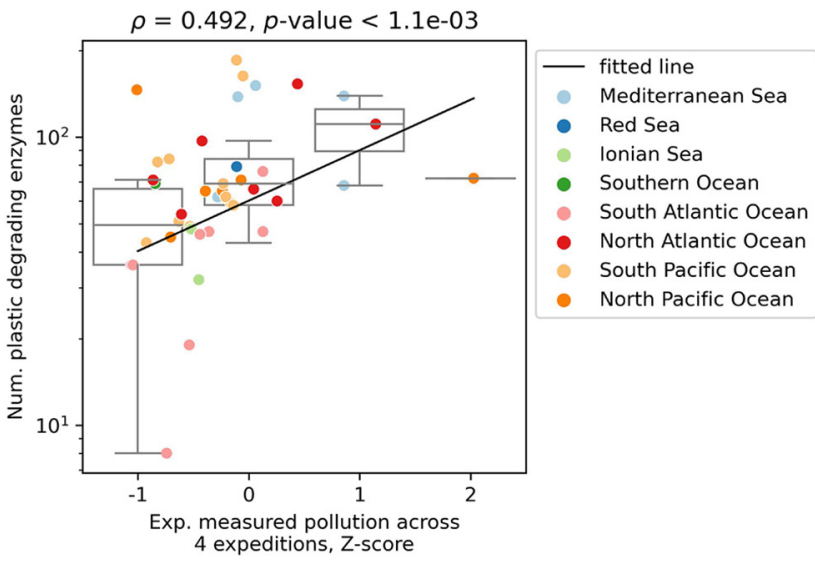

FIG 3 Plastic-degrading potential in the ocean microbiome. (A) Number of plastic-degrading enzyme hits and degradable plastic types found across 8 oceans. (B) Correlation between the number of enzyme hits and degradable plastic types with ocean environmental variables: longitude $\left({ }^{\circ}\right)$, depth (m), conductivity $(\mathrm{mS} / \mathrm{cm})$, temperature $\left({ }^{\circ} \mathrm{C}\right)$, water density $(\mathrm{kg} / \mathrm{m})$ and nitrate content ( $\mu$ mol/liter) (35). Only results with a $p$-value of $<1 \mathrm{e}-4$ are shown. $(\mathrm{C})$ Number of enzyme hits and degradable plastic types across the ocean sampling depth layers (35). (D) Number of enzyme hits relative to the number of species obtained with the metagenome-assembled genome (MAG) analysis at the phylum level (class level for Proteobacteria) (see "Metagenome assemblies and MAGs" in Materials and Methods). (Inset) Number of degradable plastic types per MAG. (E) Correlation of ocean plastic-degrading enzyme hits with experimentally measured plastic pollution across 4 ocean expeditions (51-55) (see "Enzyme function and environmental data analysis" in Materials and Methods). The black line denotes the repeated median fit (122).

(Fig. S5B). We therefore next reconstructed metagenome-assembled genomes (MAGs) in the ocean samples and predicted their taxonomies (see "Metagenome assemblies and MAGs" in Materials and Methods). The results corroborated a significant correlation (Spearman $\rho=0.392$ and 0.548; $p$-value $<2.5 e-6$ ) between the numbers of degradable plastic types and enzyme hits, respectively, with the number of unique organisms at the family level (Fig. S7A and B; similar results were obtained with other taxonomic levels). We found that, although the majority (62\%) of organisms (MAGs) were associated with a single plastic type, $2.5 \%$ of them carried enzymes corresponding to 4 or more different plastic types (Fig. 3D, inset; Fig. S7C and D). Analysis of the plastic distribution across species showed that the number of enzyme hits was significantly enriched (Fisher's exact test one-tailed $p$-value $<1.4 \mathrm{e}-05$ ) within Alphaproteobacteria and Gammaproteobacteria, which can be expected, since Proteobacteria is the most abundant and diverse phylum in the data set (Fig. 3D; Table S2). Nevertheless, the results suggested that the observed plastic-degrading enzyme abundance (Fig. 3D) might be a reflection not merely of taxonomic and functional richness but also of recently uncovered large amounts of plastic pollution below the ocean surface (47-50). 
A
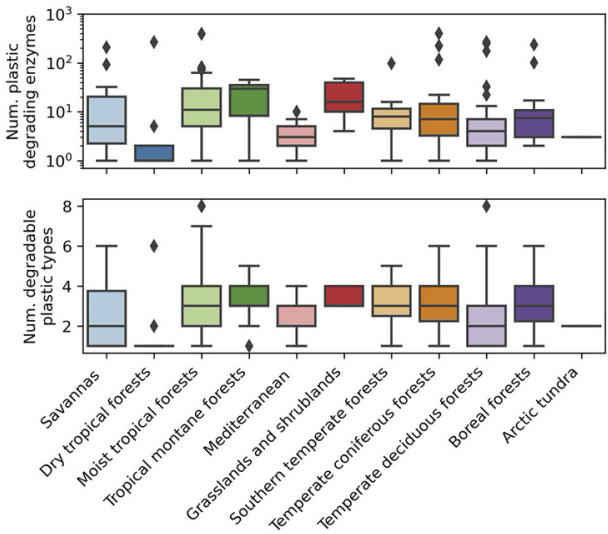

B

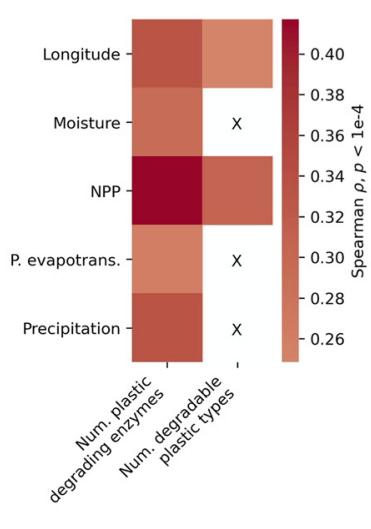

C

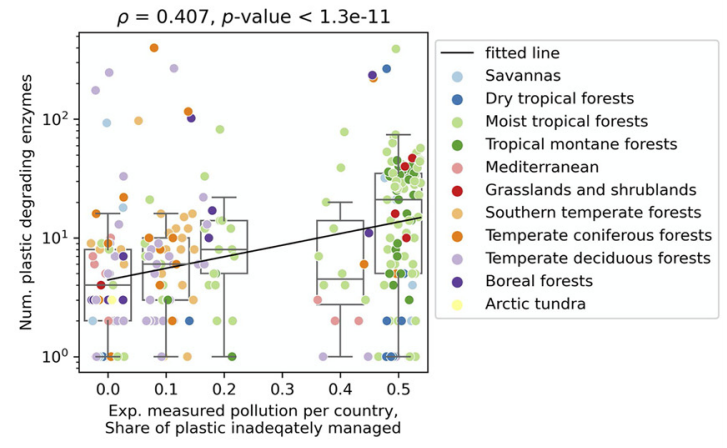

FIG 4 Plastic-degrading potential in the soil microbiome. (A) Number of plastic-degrading enzyme hits and degradable plastic types found across 11 soil habitats. (B) Correlation between the number of enzyme hits and degradable plastic types with soil environmental variables: longitude $\left({ }^{\circ}\right.$ ), average monthly moisture content (\%), net primary productivity (NPP) $\left(\mathrm{g} \mathrm{cm}^{-2}\right.$ year $\left.{ }^{-1}\right)$, and average yearly potential evapotranspiration and precipitation (liters/m ${ }^{2}$ ) (34). Only results with a $p$-value of $<1 \mathrm{e}-4$ are shown. (C) Correlation of soil plastic-degrading enzyme hits with the share of inadequately managed plastic per country (56). The black line denotes the repeated median fit (122).

The analyzed soil microbiome spanned 169 sampling locations across 38 countries and 11 distinct environmental habitats (Fig. 2; see "Enzyme function and environmental data analysis" in Materials and Methods). To ensure the accuracy of cross-habitat and cross-country comparisons, due to the different technical specifications of sample acquisition and processing across the metagenomes $(34,44,45)$, here we focused on the uniformly processed global topsoil data set (34), which also represented the largest fraction of the data (163 sampling locations) covering all given countries and habitats. A significant (rank sum test $p$-value $<4.8 \mathrm{e}-3$ ) increase of plastic-degrading enzyme hits was identified in samples from the moist tropical forest and tropical montane forest habitats compared to the other habitats (Fig. 4A; Table S1). This was corroborated by a significant correlation (Spearman $\rho$ was 0.248 and 0.332; $p$-value $<5 e-5$ ) of the numbers of both degradable plastic types and enzyme hits, respectively, with longitude as well as the number of enzyme hits with both the measured annual moisture content (Spearman $\rho=0.292 ; p$-value $=6.8 \mathrm{e}-6$ ) and precipitation levels (Spearman $\rho=0.330 ; p$-value $=4.6 \mathrm{e}-8$ ) (Fig. 4B; Fig. S5C and D). Interestingly, the soil habitats contained the most distinct differences of plastic content compared to the ocean microbiome, with all degradable plastic types present only in the moist tropical forests and temperate deciduous forests (Fig. S6B). Besides these two areas, PET, for example, was additionally found only in the Mediterranean habitat (Fig. S6B).

Since the results suggested that the plastic-degrading enzyme hits might reflect actual global pollution trends (Fig. $3 \mathrm{~A}$ and $4 \mathrm{~A}$ ), and considering that global pollution with plastics and microplastics has been an ongoing and steadily increasing problem for over 5 decades $(69,70)$, we next determined if the global potential for plastic degradation reflected measured plastic pollution in the environment. We obtained data from 4 ocean expeditions surveying plastic pollution across different oceans (51-55) and pooled it to cover $61 \%$ of the ocean sampling locations at the surface depth layer from all 8 oceans by matching the closest data points to those of the ocean sampling locations at a maximum radius of $400 \mathrm{~km}$ (see the sensitivity analysis in Table S3; see "Analysis of global plastic pollution data" in Materials and Methods; Fig. S6C). Similarly, by obtaining a data set of inadequately managed plastic waste across different countries $(56,71)$, we achieved $72 \%$ coverage of the soil samples across 35 countries (Fig. S6D). Using these common pollution data sets, we indeed observed significant correlation (Spearman $\rho=0.492$ and 0.407; $p$-value $<1.1 \mathrm{e}-3$ ) between the number of identified enzymes and pollution trends within both the ocean and soil microbiomes, respectively (Fig. 3E and 4C). Strikingly, this observed correlation between the 
abundance of plastic-degrading enzymes with global pollution suggests that the global microbiome might already be adapting to the effects of global plastic pollution.

\section{DISCUSSION}

Here, we catalogued potential plastic-degrading enzymes, including the majority of massively produced and globally polluting polymers (Fig. 1A; Fig. S1A) as well as the major additives involved in plastic production, identified from metagenomes sampled from soils and oceans across the globe (34, 35, 44, 45) (Fig. 2). We used an initial set of 95 experimentally verified published sequences and expanded it with UniProt sequences to build enzyme sequence models (hidden Markov models [63]) for mining metagenomic data (Fig. 1A and B). We identified a total of 30,000 enzyme hits in the ocean and soil microbiomes (Fig. 2) (11,906 and 18,119, respectively) corresponding to 10 major plastics types, including 6 polymers and 4 additives (Fig. 1C; Fig. S3). Nearly 60\% of identified plastic-degrading enzymes did not map to any known enzyme classes (Fig. 1D), suggesting that novel plastic-degrading functional content was uncovered, which is not surprising considering the vast numbers of novel functions uncovered in recent large-scale metagenomic studies $(33-35,50)$.

To minimize the number of false-positive hits, we used the gut microbiome (46) as a negative control (Fig. 1B; Fig. S2); that is, we assumed that this microbiome is not evolved to degrade plastics, and thus, enzyme hits that are similar to the ones found in the human gut would indicate false positives. Recent studies show that humans might ingest large amounts of plastic particles, such as micro- and nanoplastics (72), as it has recently been discovered that apart from being used in cosmetic products (73), these small particles also enter the food chain and contaminate different types of food and drink $(72,74,75)$. Plastic contaminants can have multiple adverse effects on the gut microbiome, according to studies of animal models $(74,76)$, including impairments in oxidative and inflammatory intestinal balance $(77,78)$, disruption of epithelial permeability $(78,79)$, and dysbiosis, where the symbiosis between host and the natural community and abundance pattern of the gut microbiota is disrupted $(80,81)$. Certain species, such as larvae of Plodia interpunctella (waxworms), Tenebrio molitor (mealworms), and Galleria mellonella, were even found to have developed a flora that can degrade polyethylene $(82,83)$, polystyrene $(84,85)$, or both plastic types simultaneously (86). However, these organisms might have a highly adapted and specialized microbiome due to their direct exposure and breeding in specific plastic-contaminated habitats $(82,84)$, whereas, to our knowledge, there have been no documented cases of the human gut microbiome displaying plastic-degrading properties. Therefore, as the procedure of using the human gut microbiome (46) to control for false-positive hits was highly stringent, thus reducing false-positive results at the cost of potentially losing some true hits, we presumed that this was a robust solution to ensure the validity of our findings.

A potential reason for the observed functional differences between the soil and ocean microbiomes (Fig. 1C and D; Fig. S3 and S4) could arise not only from the different plastic availability and pollution trends across these environments $(51-53,56)$ but also from the general mechanical and chemical differences between these two environments (87). For instance, the ocean is a highly dynamic environment due to its compositional medium with a large degree of mixing. As such, compared to soil, which is in large part composed of solids, one can expect an intrinsically lower community and functional stratification per unit volume in the ocean (35). The increased variability of enzyme hits and degradable plastic types across soil habitats (Fig. 1C; Fig. S7C and D), for instance, was likely a reflection of such differences. Furthermore, the large fluctuations in temperature, salinity, and mechanical forces in the ocean lead to it intrinsically possessing many polymer-degrading properties (88-90), differing from those in the soil (87) and possibly resulting in further preferences in the specific functional content. On the other hand, the soil generally contains a higher observed overall species richness $(34,91)$, and thus it is likely that certain enzyme families are overrepresented in 
each environment. This, as well as the fact that plastic additives are likely easier to degrade than the general plastic polymers due to being simpler molecules, could be the reason behind the observed large differences in the additive- versus polymer-degrading content between the ocean and soil fractions (Fig. S3 and S4). The uncovered additive-degrading enzymes in soil also likely corresponded to overrepresented but unknown enzyme classes in soil that could not be identified using the orthogonal mapping procedure $(66,67)$ (Fig. S4B). Moreover, a potentially larger amount of additive pollution on land than in the oceans might occur due to the majority of industrial activities related to production, disposal, and recycling of plastics being performed on land (92). Here, a frequent and documented problem is the early release (leaching) or migration of plastic additives, such as plasticizers, which include the phthalate compounds analyzed here $(92,93)$ (Fig. 1A). Plasticizers are most commonly used for improving the mechanical properties of polymeric films and, since they are not necessarily bound to the plastic, they are much easier to release during the use or recycling of the plastic product (92). Such migration has been shown in multiple cases for phthalate-based plasticizers (94-96), possibly leading to their contamination of different food products and the environment (97-99). These additives can potentially also be released by the application of various recycling techniques, especially in underdeveloped countries where the sorting, reprocessing, and recycling conditions are usually uncontrolled (92).

Plastics have been increasingly mass produced ever since the economic and social explosion after the second world war, with the first signs of global plastic pollution concern arising over half a century ago $(69,70)$, giving ample evolutionary time for microbial functional adaptation to these compounds $(50,100,101)$. Such adaptation was recently uncovered with $\mathrm{PET}$-degrading enzymes across ocean metagenomes of planktonic communities (50), where multiple fully functional enzyme variants were found to be evolved from ancestral enzymes degrading polycyclic aromatic hydrocarbons, suggesting that the current PET exposure already provides sufficiently strong selective pressures to direct the evolution and repurposing of such enzymes. Similarly, enzymes degrading other plastic types have been shown to be widely occurring, with numerous homologs in diverse organisms, and likely arose from well-conserved general enzyme classes $(102,103)$. Indeed, here we found multiple lines of evidence supporting the idea that the global microbiome's plastic-degrading potential reflects recent measurements of environmental plastic pollution. First, we find that taxonomic and functional richness is likely not the only driver of the observed depth stratification of enzyme hits (Fig. 3C). The organisms found to carry the largest numbers of plastic-degrading enzymes (Fig. 3D) do not completely reflect initial taxonomic estimates in the ocean (35), indicating that the plastic-degrading potential also reflects the recently uncovered trends of an increasing amount of plastic pollution below the surface $(<200 \mathrm{~m})(47)$, with considerable microplastic pollution in the mesopelagic zone (48), which are potentially stronger drivers of the observed depth stratification (50). Second, certain habitats containing the largest numbers of observed enzyme hits, such as the Mediterranean Sea and South Pacific Ocean (Fig. 3A), are known to be highly polluted areas $(53,68)$. Last, this prompted us to verify and uncover the significant measurable correlation of both ocean and soil enzyme hits with experimentally measured pollution across oceans and countries from multiple data sets (51-56) (Fig. 3E and 4C), suggesting that the earth microbiome's potential for plastic degradation is already evolving as a response to the rise in environmental pollution.

Considering that natural plastic degradation processes are very slow (e.g., the predicted life span of a PET bottle under ambient conditions ranges from 16 to 48 years [104]), the utilization of synthetic biology approaches to enhance current plastic degradation processes is crucial $(105,106)$. Moreover, although there is still unexplored diversity in microbial communities, synergistic degradation of plastics by microorganisms holds great potential to revolutionize the management of global plastic waste $(36,37)$. To this end, the methods and data on novel plastic-degrading enzymes can help researchers by 
(i) providing further information about the taxonomic diversity of such enzymes as well as understanding of the mechanisms and steps involved in the biological breakdown of plastics, (ii) pointing toward the areas with increased availability of novel enzymes, and (iii) providing a basis for further application in industrial plastic waste biodegradation. As a future perspective, more experimental data on plastic-degrading enzymes is required, with better coverage that more accurately reflects the abundance of plastic types in global waste (Fig. S1A). Improved enzyme coverage can increase the accuracy of computational results in microbial communities and uncovered distributions of plastic-degrading enzymes across different plastic types, as well as possibly enable the study of plastic degradation pathways with multiple enzymes (90).

\section{MATERIALS AND METHODS}

Enzyme data set and construction of HMMs. As initial query enzyme data, which could be used to construct hidden Markov models (HMMs) for searching across global microbiomes (Fig. S1B), we compiled a data set of 95 sequenced plastic enzymes spanning 17 plastic types with experimentally observed evidence of plastic modifying or degrading activity from published studies (10, 38-42, 57-62) and databases (43) (Data Set S1 in GitHub repository; see "Software and data" in Materials and Methods). The enzyme data set comprised 13 types of plastics and 4 types of phthalate-based plastic additives (5) (Fig. 1A). To construct the HMMs, representative sequences were first obtained from the above initial data set of enzyme sequences by clustering them using CD-HIT v4.8.1 $(107,108)$ with default settings, with the exceptions of using a word size of 5 , cluster size of 5 , and sequence identity cutoff of $95 \%$. To expand the sequence space for building the HMMs, the UniProt TrEMBL database (64) was queried with the representative enzyme sequences using BLAST+ v2.6 (109) with default settings, except for an $E$ value cutoff of $1 \mathrm{e}-10$. For each group of enzyme sequences at a given BLAST sequence identity cutoff ranging from $60 \%$ to $90 \%$ in increments of $5 \%$, representative sequences were obtained by clustering using CD-HIT with the same parameters as above. Finally, HMMs were constructed using the HMMER v3.3 hmmbuild utility (110) (http://hmmer.org/) with default settings.

Metagenome assemblies and MAGs. To construct metagenomic assemblies and metagenomeassembled genomes (MAGs) that could be queried with the HMMs, metagenomic sequencing data were obtained from the Tara Oceans expedition (35), from global (44), Australian (45), and Chinese topsoil projects (34), and from a gut microbiome study (46). From the sequencing data, metagenomic assemblies were reconstructed using MEGAHIT v1.2.9 (111) with the -presets meta-sensitive parameter, except with Tara Oceans data, where the published assemblies were used (35). MAGs were constructed for the ocean data set by first cross-mapping paired-end reads to assemblies with kallisto v0.46.1 (112) to obtain contig coverage information across samples. This information was then input to CONCOCT v1.1.0 (113) to generate a draft bin set. MetaBAT2 v.2.12.1 (114) and MaxBin2 v2.2.5 (115) were also used to generate additional draft bin sets. Finally, the three bin sets were dereplicated and reassembled using metaWRAP v1.2.3 (116) with the parameters -x 10 -c 50 to obtain the final set of MAGs (117). Default settings were used except where otherwise stated.

HMM queries across metagenomes and data filtering. For identifying homologous sequences in metagenomes using the constructed HMMs, hmmsearch from HMMER v3.3 (110) was used with default settings. Furthermore, to minimize the risk of false-positive results, we filtered the environmental hits by comparing their bit score to those obtained with the gut microbiome. For each HMM, precision, recall, and the area under the precision-recall curve (AUC) were computed by comparing the corresponding hits in the global microbiomes to those in the gut microbiome. Only models with a minimum of 20 data points and hits in the global microbiomes with an E-value cutoff below $1 \mathrm{e}-16$ and scores above a precision threshold of $99.99 \%$ and AUC of $75 \%$ were retained. Additionally, only the lowest $E$-value and bit score hit were retained for each gene in the global metagenomes. Consequently, the HMM queries across metagenomes identified a total of 30,025 homologous plastic-degrading enzyme hits nonredundant at the amino acid level, comprising 11,906 hits in the ocean and 18,119 in the soil data set (Table 1; see Data Set S2 in the GitHub repository; see "Software and data" in Materials and Methods). The precision-recall analysis was performed using Scikit-learn v0.23.1 (118) with default settings.

Enzyme function and environmental data analysis. To annotate the identified plastic-degrading enzyme hits with EC enzyme classifications, we performed orthologous function mapping using Eggnog-mapper v2 $(66,67)$ with default settings. This led to $41 \%$ of the enzyme hits being functionally annotated and used to analyze and compare enzyme functions within and between the microbiome fractions.

Environmental data for the ocean and soil microbiomes were obtained from the supplementary information attached to the respective Tara Oceans (35) and global topsoil (34) publications, with additional data obtained as follows: (i) Tara Oceans data from the PANGEA database (www.pangaea.de) (35) and (ii) global topsoil data from the Atlas of the Biosphere (https://nelson.wisc.edu/sage/data-and -models/atlas/maps.php), with the exception of temperature and precipitation data, which were obtained from the WorldClim database (https://www.worldclim.org/) (34). For the ocean microbiome analysis, the prokaryote-enriched fraction of the ocean data was used by filtering for size-fractionated samples targeting organisms between 0.22 and $3 \mu \mathrm{m}$ (35). The depth layers at which the ocean microbiome was sampled included (i) the surface water layer (SRF; mean \pm standard deviation [SD] of $5 \pm 0 \mathrm{~m}$, 63 samples), (ii) the deep chlorophyll maximum (DCM; $71 \pm 41 \mathrm{~m}, 46$ samples) layer, and (iii) the 
mesopelagic zone (MES; $600 \pm 220 \mathrm{~m}, 30$ samples) (35). The soil microbiome analysis was performed with the global topsoil data set (34) (Table 1) that incorporated the corresponding environmental data unified across all samples, with the 11 environmental habitats used as defined by Bahram et al. (34): arctic tundra ( 1 sample), boreal forests (14 samples), dry tropical forests ( 9 samples), grasslands and shrublands (5 samples), Mediterranean (13 samples), moist tropical forests (88 samples), savannas (14 samples), southern temperate forests (23 samples), temperate coniferous forests (18 samples), temperate deciduous forests (42 samples), and tropical montane forests (34 samples).

For statistical hypothesis testing, SciPy v1.1.0 (119) was used with default settings. All statistical tests were two tailed unless stated otherwise. For correlation analysis, the Spearman correlation coefficient was used. To explore the overall variability in the composition of identified enzyme hits, principal-coordinate analysis (PCoA) was performed using Scikit-bio v0.5.5 (http://scikit-bio.org/) with default settings and the Bray-Curtis distance.

Analysis of global plastic pollution data. To analyze if the identified plastic-degrading enzyme hits reflect current global plastic pollution trends, we obtained experimentally measured ocean and countryspecific pollution data. For the ocean pollution analysis, data were obtained from 4 published ocean expedition measurements (51-55) either from the supplementary information attached to each publication or from the authors upon email request $(54,55)$. Since the data were obtained at different specific ocean regions and, on average, corresponded to merely $\sim 10$ microbiome sampling locations per pollution data set, we constructed a single combined data set of pollution measurements that could facilitate the correlation analysis. For this, the data were pooled by standardizing the values using the Box-Cox transform (120) and computing z-scores. With the ocean microbiome sampling locations with identified enzyme hits, only sampling locations corresponding to the surface layer were used, as the pollution measurements were also performed at the ocean surface layer. To determine the optimal distance cutoff, based on which the plastic pollution data were assigned to each microbiome sampling location with identified enzyme hits, a sensitivity analysis was performed at different distance cutoffs, with a radius of $400 \mathrm{~km}$ being identified as optimal (Table S3). At each distance cutoff, only the closest pollution measurement point was retained for each sampling location. Similarly, for the soil pollution analysis, published pollution data on inadequately managed plastic waste across different countries (56) were obtained from an online data repository (71) and were standardized using the Box-Cox transform and by computing z-scores. The data on the amount of waste generated in 2010 per plastic type (1) was obtained from the authors upon email request. The Spearman correlation coefficient was used for the correlation analysis between the numerical variables, with numerical range-specific box plots in Fig. $3 \mathrm{E}$ and $4 \mathrm{C}$ shown to aid data visualization.

Software and data. Snakemake v5.10.0 (121), Python v3.6 (www.python.org), and R v3.6 (www.r-project .org) were used for computations. Code for the data analysis and supplementary data sets are available at https://github.com/JanZrimec/Plastic_degrading_microbiome, with additional data to reproduce the analysis published at https://doi.org/10.5281/zenodo.5112372.

\section{SUPPLEMENTAL MATERIAL}

Supplemental material is available online only.

FIG S1, JPG file, 1.2 MB.

FIG S2, JPG file, $0.3 \mathrm{MB}$.

FIG S3, JPG file, $0.4 \mathrm{MB}$.

FIG S4, JPG file, 2.2 MB.

FIG S5, JPG file, 2.6 MB.

FIG S6, JPG file, 1.5 MB.

FIG S7, JPG file, $1 \mathrm{MB}$.

TABLE S1, TXT file, $0.001 \mathrm{MB}$.

TABLE S2, TXT file, $0.001 \mathrm{MB}$.

TABLE S3, TXT file, $0.001 \mathrm{MB}$.

\section{ACKNOWLEDGMENTS}

We thank Roland Geyer, Nikolai Maximenko, Laurent Lebreton, and Jose Borrero for kindly sharing their data. We also thank Gregg Treinish and Abigail Burrows for providing access to Adventure Scientists data on plastic pollution. The computations were enabled with resources provided by the Swedish National Infrastructure for Computing (SNIC) at C3SE partially funded by the Swedish Research Council through grant agreement no. 2018-05973. Mikael Öhman and Thomas Svedberg at C3SE are acknowledged for technical assistance in making the code run on Vera C3SE resources.

The study was supported by SciLifeLab funding and Formas early-career research grant 2019-01403.

J.Z. and A.Z. conceptualized the project; J.Z., S.J., F.Z., and A.Z. designed the computational analysis; J.Z., M.K., S.J., F.Z., and A.Z. performed the computational 
analysis; J.Z. and A.Z. interpreted the results; J.Z. wrote the draft manuscript; J.Z. and

A.Z. revised the draft and wrote the final manuscript.

We declare no competing interests.

\section{REFERENCES}

1. Geyer R, Jambeck JR, Law KL. 2017. Production, use, and fate of all plastics ever made. Sci Adv 3:e1700782. https://doi.org/10.1126/sciadv .1700782 .

2. Lau WWY, Shiran Y, Bailey RM, Cook E, Stuchtey MR, Koskella J, Velis CA, Godfrey L, Boucher J, Murphy MB, Thompson RC, Jankowska E, Castillo Castillo A, Pilditch TD, Dixon B, Koerselman L, Kosior E, Favoino E, Gutberlet J, Baulch S, Atreya ME, Fischer D, He KK, Petit MM, Sumaila UR, Neil E, Bernhofen MV, Lawrence K, Palardy JE. 2020. Evaluating scenarios toward zero plastic pollution. Science 369:1455-1461. https://doi.org/10 $.1126 /$ science.aba9475.

3. Ocean Conservancy. 2015. Stemming the tide: land-based strategies for a plastic-free ocean.

4. Sathyanarayana S, Alcedo G, Saelens BE, Zhou C, Dills RL, Yu J, Lanphear B. 2013. Unexpected results in a randomized dietary trial to reduce phthalate and bisphenol A exposures. J Expo Sci Environ Epidemiol 23: 378-384. https://doi.org/10.1038/jes.2013.9.

5. Meeker JD, Sathyanarayana S, Swan SH. 2009. Phthalates and other additives in plastics: human exposure and associated health outcomes. Philos Trans R Soc Lond B Biol Sci 364:2097-2113. https://doi.org/10.1098/rstb .2008.0268.

6. Sharma A, Aloysius V, Visvanathan C. 2019. Recovery of plastics from dumpsites and landfills to prevent marine plastic pollution in Thailand. Waste Dispos Sustain Energy 1:237-249. https://doi.org/10.1007/s42768 -019-00027-7.

7. Hopewell J, Dvorak R, Kosior E. 2009. Plastics recycling: challenges and opportunities. Philos Trans R Soc Lond B Biol Sci 364:2115-2126. https:// doi.org/10.1098/rstb.2008.0311.

8. Chen C-C, Dai L, Ma L, Guo R-T. 2020. Enzymatic degradation of plant biomass and synthetic polymers. Nat Rev Chem 4:114-126. https://doi.org/ 10.1038/s41570-020-0163-6.

9. Bank MS, Hansson SV. 2019. The plastic cycle: a novel and holistic paradigm for the Anthropocene. Environ Sci Technol 53:7177-7179. https:// doi.org/10.1021/acs.est.9b02942.

10. Yoshida S, Hiraga K, Takehana T, Taniguchi I, Yamaji H, Maeda Y, Toyohara K, Miyamoto K, Kimura Y, Oda K. 2016. A bacterium that degrades and assimilates poly(ethylene terephthalate). Science 351:1196-1199. https:// doi.org/10.1126/science.aad6359.

11. Gaytan I, Sanchez-Reyes A, Burelo M, Vargas-Suarez M, Liachko I, Press M, Sullivan S, Cruz-Gomez MJ, Loza-Tavera H. 2020. Degradation of recalcitrant polyurethane and xenobiotic additives by a selected landfill microbial community and its biodegradative potential revealed by proximity ligation-based metagenomic analysis. Front Microbiol 10:2986. https://doi.org/10.3389/fmicb.2019.02986.

12. Ji JB, Zhang YT, Liu YC, Zhu PP, Yan X. 2020. Biodegradation of plastic monomer 2,6-dimethylphenol by Mycobacterium neoaurum B5-4. Environ Pollut 258:113793. https://doi.org/10.1016/j.envpol.2019.113793.

13. Kumar A, Gudiukaite R, Gricajeva A, Sadauskas M, Malunavicius V, Kamyab H, Sharma S, Sharma T, Pant D. 2020. Microbial lipolytic enzymes-promising energy-efficient biocatalysts in bioremediation. Energy 192:116674. https://doi.org/10.1016/j.energy.2019.116674.

14. Rosato A, Barone M, Negroni A, Brigidi P, Fava F, Xu P, Candela M, Zanaroli G. 2020. Microbial colonization of different microplastic types and biotransformation of sorbed PCBs by a marine anaerobic bacterial community. Sci Total Environ 705:135790. https://doi.org/10.1016/j .scitotenv.2019.135790.

15. Urbanek AK, Urbanek AK, Mironczuk AM, Barcia-Martin A, Saborido A, de la Mata I, Arroyo M. 2020. Biochemical properties and biotechnological applications of microbial enzymes involved in the degradation of polyester-type plastics. Biochim Biophys Acta Proteins Proteom 1868:140315. https://doi.org/10.1016/j.bbapap.2019.140315.

16. Yuan JH, Ma J, Sun Y, Zhou T, Zhao Y, Yu F. 2020. Microbial degradation and other environmental aspects of microplastics/plastics. Sci Total Environ 715:136968. https://doi.org/10.1016/j.scitotenv.2020.136968.

17. Bittner N, Nefzger H, Behnken G, Jaeger G, Behnken S, Reisky L. 2020. Novel urethanases for the enzymatic decomposition of polyurethanes. European patent application EP3587570A1.
18. Dussud $C$, Meistertzheim AL, Conan $P$, Pujo-Pay $M$, George $M$, Fabre $P$, Coudane J, Higgs P, Elineau A, Pedrotti ML, Gorsky G, Ghiglione JF. 2018. Evidence of niche partitioning among bacteria living on plastics, organic particles and surrounding seawaters. Environ Pollut 236:807-816. https://doi.org/10.1016/j.envpol.2017.12.027.

19. Oberbeckmann S, Loeder MGJ, Gerdts G, Osborn AM. 2014. Spatial and seasonal variation in diversity and structure of microbial biofilms on marine plastics in Northern European waters. FEMS Microbiol Ecol 90: 478-492. https://doi.org/10.1111/1574-6941.12409.

20. Oberbeckmann S, Kreikemeyer B, Labrenz M. 2017. Environmental factors support the formation of specific bacterial assemblages on microplastics. Front Microbiol 8:2709. https://doi.org/10.3389/fmicb.2017.02709.

21. De Tender CA, Devriese LI, Haegeman A, Maes S, Ruttink T, Dawyndt P. 2015. Bacterial community profiling of plastic litter in the Belgian part of the North Sea. Environ Sci Technol 49:9629-9638. https://doi.org/10 .1021/acs.est.5b01093.

22. Skariyachan S, Patil AA, Shankar A, Manjunath M, Bachappanavar N, Kiran S. 2018. Enhanced polymer degradation of polyethylene and polypropylene by novel thermophilic consortia of Brevibacillus sps. and Aneurinibacillus sp. screened from waste management landfills and sewage treatment plants. Polym Degrad Stab 149:52-68. https://doi.org/10 .1016/j.polymdegradstab.2018.01.018.

23. Janatunaim RZ, Fibriani A. 2020. Construction and cloning of plasticdegrading recombinant enzymes (MHETase). Recent Pat Biotechnol 14: 229-234. https://doi.org/10.2174/1872208314666200311104541.

24. Munir E, Harefa RSM, Priyani N, Suryanto D. 2018. Plastic degrading fungi Trichoderma viride and Aspergillus nomius isolated from local landfill soil in Medan. IOP Conf Ser Earth Environ Sci 126:e012145. https://doi org/10.1088/1755-1315/126/1/012145.

25. Bardají DKR, Furlan JPR, Stehling EG. 2019. Isolation of a polyethylene degrading Paenibacillus sp. from a landfill in Brazil. Arch Microbiol 201: 699-704. https://doi.org/10.1007/s00203-019-01637-9.

26. Gupta KK, Devi D. 2017. Isolation and characterization of low density polyethylene degrading Bacillus spp. from garbage dump sites. World J Pharm Sci 6:609-617.

27. Skariyachan S, Manjunatha V, Sultana S, Jois C, Bai V, Vasist KS. 2016. Novel bacterial consortia isolated from plastic garbage processing areas demonstrated enhanced degradation for low density polyethylene. Environ Sci Pollut Res 23:18307-18319. https://doi.org/10.1007/s11356-016 $-7000-y$.

28. Sarmah P, Rout J. 2018. Efficient biodegradation of low-density polyethylene by cyanobacteria isolated from submerged polyethylene surface in domestic sewage water. Environ Sci Pollut Res Int 25:33508-33520. https://doi.org/10.1007/s11356-018-3079-7.

29. Tramontano $M$, Andrejev $S$, Pruteanu $M$, Klünemann $M$, Kuhn $M$, Galardini M, Jouhten P, Zelezniak A, Zeller G, Bork P, Typas A, Patil KR. 2018. Nutritional preferences of human gut bacteria reveal their metabolic idiosyncrasies. Nat Microbiol 3:514-522. https://doi.org/10.1038/ s41564-018-0123-9.

30. Berini F, Casciello C, Marcone GL, Marinelli F. 2017. Metagenomics: novel enzymes from non-culturable microbes. FEMS Microbiol Lett 364. https://doi.org/10.1093/femsle/fnx211.

31. Carniel A, Valoni E, Nicomedes J, Gomes AD, de Castro AM. 2017. Lipase from Candida antarctica (CALB) and cutinase from Humicola insolens act synergistically for PET hydrolysis to terephthalic acid. Process Biochem 59:84-90. https://doi.org/10.1016/j.procbio.2016.07.023.

32. Zettler ER, Mincer TJ, Amaral-Zettler LA. 2013. Life in the 'plastisphere': microbial communities on plastic marine debris. Environ Sci Technol 47: 7137-7146. https://doi.org/10.1021/es401288x.

33. Ferrer M, Martínez-Martínez M, Bargiela R, Streit WR, Golyshina OV, Golyshin PN. 2016. Estimating the success of enzyme bioprospecting through metagenomics: current status and future trends. Microb Biotechnol 9:22-34. https://doi.org/10.1111/1751-7915.12309.

34. Bahram M, Hildebrand F, Forslund SK, Anderson JL, Soudzilovskaia NA, Bodegom PM, Bengtsson-Palme J, Anslan S, Coelho LP, Harend $H$, Huerta-Cepas J, Medema MH, Maltz MR, Mundra S, Olsson PA, Pent M, 
Põlme S, Sunagawa S, Ryberg M, Tedersoo L, Bork P. 2018. Structure and function of the global topsoil microbiome. Nature 560:233-237. https:// doi.org/10.1038/s41586-018-0386-6.

35. Sunagawa S, Coelho LP, Chaffron S, Kultima JR, et al. 2015. Ocean plankton. Structure and function of the global ocean microbiome. Science 348:1261359. https://doi.org/10.1126/science.1261359.

36. Danso D, Chow J, Streit WR. 2019. Plastics: environmental and biotechnological perspectives on microbial degradation. Appl Environ Microbiol 85:e01095-19. https://doi.org/10.1128/AEM.01095-19.

37. Roager L, Sonnenschein EC. 2019. Bacterial candidates for colonization and degradation of marine plastic debris. Environ Sci Technol 53: 11636-11643. https://doi.org/10.1021/acs.est.9b02212.

38. Miyakawa T, Mizushima H, Ohtsuka J, Oda M, Kawai F, Tanokura M. 2015. Structural basis for the $\mathrm{Ca}(2+)$-enhanced thermostability and activity of PET-degrading cutinase-like enzyme from Saccharomonospora viridis AHK190. Appl Microbiol Biotechnol 99:4297-4307. https://doi.org/10 .1007/s00253-014-6272-8.

39. Herrero Acero E, Ribitsch D, Steinkellner G, Gruber K, Greimel K, Eiteljoerg I, Trotscha E, Wei R, Zimmermann W, Zinn M, Cavaco-Paulo A, Freddi G, Schwab H, Guebitz G. 2011. Enzymatic surface hydrolysis of PET: effect of structural diversity on kinetic properties of cutinases from Thermobifida. Macromolecules 44:4632-4640. https://doi.org/10.1021/ ma200949p.

40. Roth C, Wei R, Oeser T, Then J, Föllner C, Zimmermann W, Sträter N. 2014. Structural and functional studies on a thermostable polyethylene terephthalate degrading hydrolase from Thermobifida fusca. Appl Microbiol Biotechnol 98:7815-7823. https://doi.org/10.1007/s00253-014-5672-0.

41. Oelschlägel M, Zimmerling J, Schlömann M, Tischler D. 2014. Styrene oxide isomerase of Sphingopyxis sp. Kp5.2. Microbiology (Reading) 160: 2481-2491. https://doi.org/10.1099/mic.0.080259-0.

42. Oelschlägel M, Gröning JAD, Tischler D, Kaschabek SR, Schlömann M. 2012. Styrene oxide isomerase of Rhodococcus opacus $1 C P$, a highly stable and considerably active enzyme. Appl Environ Microbiol 78: 4330-4337. https://doi.org/10.1128/AEM.07641-11.

43. Gan Z, Zhang H. 2019. PMBD: a comprehensive plastics microbial biodegradation database. Database 2019:baz119. https://doi.org/10 $.1093 /$ database/baz119.

44. Li X, Jousset A, de Boer W, Carrión VJ, Zhang T, Wang X, Kuramae EE. 2019. Legacy of land use history determines reprogramming of plant physiology by soil microbiome. ISME J 13:738-751. https://doi.org/10 .1038/s41396-018-0300-0.

45. Bissett A, Fitzgerald A, Court L, Meintjes T, Mele PM, Reith F, Dennis PG, Breed MF, Brown B, Brown MV, Brugger J, Byrne M, Caddy-Retalic S, Carmody B, Coates DJ, Correa C, Ferrari BC, Gupta VVSR, Hamonts K, Haslem A, Hugenholtz P, Karan M, Koval J, Lowe AJ, Macdonald S, McGrath L, Martin D, Morgan M, North KI, Paungfoo-Lonhienne C, Pendall E, Phillips L, Pirzl R, Powell JR, Ragan MA, Schmidt S, Seymour N, Snape I, Stephen JR, Stevens M, Tinning M, Williams K, Yeoh YK, Zammit CM, Young A. 2016. Introducing BASE: the Biomes of Australian Soil Environments soil microbial diversity database. Gigascience 5:21. https://doi .org/10.1186/s13742-016-0126-5.

46. Karlsson FH, Tremaroli V, Nookaew I, Bergström G, Behre CJ, Fagerberg B, Nielsen J, Bäckhed F. 2013. Gut metagenome in European women with normal, impaired and diabetic glucose control. Nature 498:99-103. https:// doi.org/10.1038/nature12198.

47. Pabortsava K, Lampitt RS. 2020. High concentrations of plastic hidden beneath the surface of the Atlantic Ocean. Nat Commun 11:4073. https://doi.org/10.1038/s41467-020-17932-9.

48. Choy CA, Robison BH, Gagne TO, Erwin B, Firl E, Halden RU, Hamilton JA, Katija K, Lisin SE, Rolsky C, S Van Houtan K. 2019. The vertical distribution and biological transport of marine microplastics across the epipelagic and mesopelagic water column. Sci Rep 9:7843. https://doi.org/10.1038/ s41598-019-44117-2.

49. Woodall LC, Sanchez-Vidal A, Canals M, Paterson GLJ, Coppock R, Sleight V, Calafat A, Rogers AD, Narayanaswamy BE, Thompson RC. 2014. The deep sea is a major sink for microplastic debris. R Soc Open Sci 1:140317. https://doi.org/10.1098/rsos.140317.

50. Alam I, et al. 2020. Rapid evolution of plastic-degrading enzymes prevalent in the global ocean. bioRxiv https://doi.org/10.1101/2020.09.07 .285692 .

51. Eriksen M, Lebreton LCM, Carson HS, Thiel M, Moore CJ, Borerro JC, Galgani F, Ryan PG, Reisser J. 2014. Plastic pollution in the world's oceans: more than 5 trillion plastic pieces weighing over 250,000 tons afloat at sea. PLoS One 9:e111913. https://doi.org/10.1371/journal.pone.0111913.
52. Goldstein MC, Rosenberg M, Cheng L. 2012. Increased oceanic microplastic debris enhances oviposition in an endemic pelagic insect. Biol Lett 8:817-820. https://doi.org/10.1098/rsbl.2012.0298.

53. Law KL, Morét-Ferguson SE, Goodwin DS, Zettler ER, Deforce E, Kukulka T, Proskurowski G. 2014. Distribution of surface plastic debris in the eastern Pacific Ocean from an 11-year data set. Environ Sci Technol 48: 4732-4738. https://doi.org/10.1021/es4053076.

54. Barrows A. 2016. Understanding microplastic distribution: a global citizen monitoring effort, p 22. In Baztan J, Jorgensen B, Pahl S, Thompson RC, Vanderlinden J-P (ed), MICRO 2016. Fate and Impact of Microplastics in Marine Ecosystems. Elsevier, Amsterdam, The Netherlands.

55. Christiansen KS. 2018. Global and gallatin microplastics initiatives. Adventure Scientists, Bozeman, MT.

56. Jambeck JR, Geyer R, Wilcox C, Siegler TR. 2015. Plastic waste inputs from land into the ocean. Science 347:768-771. https://doi.org/10.1126/ science.1260352.

57. Dresler K, van den Heuvel J, Müller R-J, Deckwer W-D. 2006. Production of a recombinant polyester-cleaving hydrolase from Thermobifida fusca in Escherichia coli. Bioprocess Biosyst Eng 29:169-183. https://doi.org/10 .1007/s00449-006-0069-9.

58. Vega RE, Main T, Howard GT. 1999. Cloning and expression in Escherichia coli of apolyurethane-degrading enzyme from Pseudomonasfluorescens. Int Biodeterior Biodegrad 43:49-55. https://doi.org/10.1016/S0964 -8305(98)00068-7.

59. Matsubara M, Suzuki J, Deguchi T, Miura M, Kitaoka Y. 1996. Characterization of manganese peroxidases from the hyperlignolytic fungus IZU154. Appl Environ Microbiol 62:4066-4072. https://doi.org/10.1128/aem .62.11.4066-4072.1996.

60. Nakamura K, Tomita T, Abe N, Kamio Y. 2001. Purification and characterization of an extracellular poly(L-lactic acid) depolymerase from a soil isolate, Amycolatopsis sp. strain K104-1. Appl Environ Microbiol 67:345-353. https://doi.org/10.1128/AEM.67.1.345-353.2001.

61. Matsuda E, Abe N, Tamakawa H, Kaneko J, Kamio Y. 2005. Gene cloning and molecular characterization of an extracellular poly(L-lactic acid) depolymerase from Amycolatopsis sp. strain K104-1. J Bacteriol 187: 7333-7340. https://doi.org/10.1128/JB.187.21.7333-7340.2005.

62. Beltrametti F, Marconi AM, Bestetti G, Colombo C, Galli E, Ruzzi M, Zennaro E. 1997. Sequencing and functional analysis of styrene catabolism genes from Pseudomonas fluorescens ST. Appl Environ Microbiol 63:2232-2239. https://doi.org/10.1128/aem.63.6.2232-2239.1997.

63. Eddy SR. 2004. What is a hidden Markov model?? Nat Biotechnol 22: 1315-1316. https://doi.org/10.1038/nbt1004-1315.

64. The UniProt Consortium. 2016. UniProt: the universal protein knowledgebase. Nucleic Acids Res 45:D158-D169. https://doi.org/10.1093/ nar/gkw1099.

65. Tian W, Skolnick J. 2003. How well is enzyme function conserved as a function of pairwise sequence identity?? J Mol Biol 333:863-882. https:// doi.org/10.1016/j.jmb.2003.08.057.

66. Huerta-Cepas J, Szklarczyk D, Heller D, Hernández-Plaza A, Forslund SK, Cook H, Mende DR, Letunic I, Rattei T, Jensen $L$, von Mering C, Bork P. 2019. eggNOG 5.0: a hierarchical, functionally and phylogenetically annotated orthology resource based on 5090 organisms and 2502 viruses. Nucleic Acids Res 47:D309-D314. https://doi.org/10.1093/nar/gky1085.

67. Huerta-Cepas J, Forslund K, Coelho LP, Szklarczyk D, Jensen L, von Mering C, Bork P. 2017. Fast genome-wide functional annotation through orthology assignment by eggNOG-Mapper. Mol Biol Evol 34:2115-2122. https:// doi.org/10.1093/molbev/msx148.

68. Cózar A, Sanz-Martín M, Martí E, González-Gordillo Jl, Ubeda B, Gálvez JÁ, Irigoien X, Duarte CM. 2015. Plastic accumulation in the Mediterranean Sea. PLoS One 10:e0121762. https://doi.org/10.1371/journal.pone .0121762 .

69. Ryan PG. 2015. A brief history of marine litter research, p 1-25. In Bergmann M, Gutow L, Klages M (ed), Marine anthropogenic litter. Springer, Cham, Switzerland.

70. Carpenter EJ, Smith KL, Jr. 1972. Plastics on the Sargasso sea surface. Science 175:1240-1241. https://doi.org/10.1126/science.175.4027.1240.

71. Ritchie H, Roser M. 2018. Plastic pollution. Our World in Data.

72. Paul MB, Stock V, Cara-Carmona J, Lisicki E, Shopova S, Fessard V, Braeuning A, Sieg H, Böhmert L. 2020. Micro- and nanoplastics-current state of knowledge with the focus on oral uptake and toxicity. Nanoscale Adv 2:4350-4367. https://doi.org/10.1039/DONA00539H.

73. Leslie HA. 2014. Review of microplastics in cosmetics. IVM Institute for Environmental Studies, Amsterdam, The Netherlands. 
74. Hirt N, Body-Malapel M. 2020. Immunotoxicity and intestinal effects of nano- and microplastics: a review of the literature. Part Fibre Toxicol 17: 57. https://doi.org/10.1186/s12989-020-00387-7.

75. Fournier E, Etienne-Mesmin L, Grootaert C, Jelsbak L, Syberg K, BlanquetDiot S, Mercier-Bonin M. 2021. Microplastics in the human digestive environment: a focus on the potential and challenges facing in vitro gut model development. J Hazard Mater 415:125632. https://doi.org/10 .1016/j.jhazmat.2021.125632.

76. Lu L, Luo T, Zhao Y, Cai C, Fu Z, Jin Y. 2019. Interaction between microplastics and microorganism as well as gut microbiota: a consideration on environmental animal and human health. Sci Total Environ 667:94-100. https://doi.org/10.1016/j.scitotenv.2019.02.380.

77. Lei L, Wu S, Lu S, Liu M, Song Y, Fu Z, Shi H, Raley-Susman KM, He D. 2018. Microplastic particles cause intestinal damage and other adverse effects in zebrafish Danio rerio and nematode Caenorhabditis elegans. Sci Total Environ 619-620:1-8. https://doi.org/10.1016/j.scitotenv.2017 .11.103.

78. Qiao R, Sheng C, Lu Y, Zhang Y, Ren H, Lemos B. 2019. Microplastics induce intestinal inflammation, oxidative stress, and disorders of metabolome and microbiome in zebrafish. Sci Total Environ 662:246-253. https://doi.org/10.1016/j.scitotenv.2019.01.245.

79. Deng Y, Yan Z, Shen R, Wang M, Huang Y, Ren H, Zhang Y, Lemos B. 2020. Microplastics release phthalate esters and cause aggravated adverse effects in the mouse gut. Environ Int 143:105916. https://doi .org/10.1016/j.envint.2020.105916.

80. Wan Z, Wang C, Zhou J, Shen M, Wang X, Fu Z, Jin Y. 2019. Effects of polystyrene microplastics on the composition of the microbiome and metabolism in larval zebrafish. Chemosphere 217:646-658. https://doi .org/10.1016/j.chemosphere.2018.11.070.

81. Fackelmann G, Sommer S. 2019. Microplastics and the gut microbiome: how chronically exposed species may suffer from gut dysbiosis. Mar Pollut Bull 143:193-203. https://doi.org/10.1016/j.marpolbul.2019.04.030.

82. Yang J, Yang Y, Wu W-M, Zhao J, Jiang L. 2014. Evidence of polyethylene biodegradation by bacterial strains from the guts of plastic-eating waxworms. Environ Sci Technol 48:13776-13784. https://doi.org/10.1021/ es504038a.

83. Cassone BJ, Grove HC, Elebute O, Villanueva SMP, LeMoine CMR. 2020. Role of the intestinal microbiome in low-density polyethylene degradation by caterpillar larvae of the greater wax moth, Galleria mellonella. Proc Biol Sci 287:20200112.

84. Yang Y, Yang J, Wu W-M, Zhao J, Song Y, Gao L, Yang R, Jiang L. 2015. Biodegradation and mineralization of polystyrene by plastic-eating mealworms: part 2. Role of gut microorganisms. Environ Sci Technol 49: 12087-12093. https://doi.org/10.1021/acs.est.5b02663.

85. Urbanek AK, Rybak J, Wróbel M, Leluk K, Mirończuk AM. 2020. A comprehensive assessment of microbiome diversity in Tenebrio molitor fed with polystyrene waste. Environ Pollut 262:114281. https://doi.org/10 .1016/j.envpol.2020.114281.

86. Brandon AM, Gao S-H, Tian R, Ning D, Yang S-S, Zhou J, Wu W-M, Criddle CS. 2018. Biodegradation of polyethylene and plastic mixtures in mealworms (larvae of Tenebrio molitor) and effects on the gut microbiome. Environ Sci Technol 52:6526-6533. https://doi.org/10.1021/acs.est.8b02301.

87. Chamas A, Moon H, Zheng J, Qiu Y. 2020. Degradation rates of plastics in the environment. ACS Sustainable Chem Eng 8:3494-3511. https://doi .org/10.1021/acssuschemeng.9b06635.

88. Lucas N, Bienaime C, Belloy C, Queneudec M, Silvestre F, Nava-Saucedo J-E. 2008. Polymer biodegradation: mechanisms and estimation techniques-a review. Chemosphere 73:429-442. https://doi.org/10.1016/j .chemosphere.2008.06.064.

89. Min K, Cuiffi JD, Mathers RT. 2020. Ranking environmental degradation trends of plastic marine debris based on physical properties and molecular structure. Nat Commun 11:727. https://doi.org/10.1038/s41467-020 $-14538-z$.

90. Gewert B, Plassmann MM, MacLeod M. 2015. Pathways for degradation of plastic polymers floating in the marine environment. Environ Sci Process Impacts 17:1513-1521. https://doi.org/10.1039/c5em00207a.

91. Walters KE, Martiny JBH. 2020. Alpha-, beta-, and gamma-diversity of bacteria varies across global habitats. PloS One 15(9):e0233872. https:// doi.org/10.1371/journal.pone.0233872.

92. Hahladakis JN, Velis CA, Weber R, lacovidou E, Purnell P. 2018. An overview of chemical additives present in plastics: migration, release, fate and environmental impact during their use, disposal and recycling. J Hazard Mater 344:179-199. https://doi.org/10.1016/j.jhazmat.2017.10.014.
93. de Souza Machado AA, Kloas W, Zarfl C, Hempel S, Rillig MC. 2018. Microplastics as an emerging threat to terrestrial ecosystems. Glob Change Biol 24:1405-1416. https://doi.org/10.1111/gcb.14020.

94. Fankhauser-Noti A, Grob K. 2006. Migration of plasticizers from PVC gaskets of lids for glass jars into oily foods: amount of gasket material in food contact, proportion of plasticizer migrating into food and compliance testing by simulation. Trends Food Sci Technol 17:105-112. https:// doi.org/10.1016/j.tifs.2005.10.013.

95. Fasano E, Bono-Blay F, Cirillo T, Montuori P, Lacorte S. 2012. Migration of phthalates, alkylphenols, bisphenol A and di(2-ethylhexyl)adipate from food packaging. Food Control 27:132-138. https://doi.org/10.1016/j foodcont.2012.03.005.

96. Li C, Xu J, Chen D, Xiao Y. 2016. Detection of phthalates migration from disposable tablewares to drinking water using hexafluoroisopropanolinduced catanionic surfactant coacervate extraction. J Pharm Anal 6: 292-299. https://doi.org/10.1016/j.jpha.2016.04.002.

97. Main KM, Mortensen GK, Kaleva MM, Boisen KA, Damgaard IN, Chellakooty M, Schmidt IM, Suomi A-M, Virtanen HE, Petersen JH, Andersson A-M, Toppari J, Skakkebæk NE. 2006. Human breast milk contamination with phthalates and alterations of endogenous reproductive hormones in infants three months of age. Environ Health Perspect 114: 270-276. https://doi.org/10.1289/ehp.8075.

98. Clarke BO, Smith SR. 2011. Review of 'emerging' organic contaminants in biosolids and assessment of international research priorities for the agricultural use of biosolids. Environ Int 37:226-247. https://doi.org/10 .1016/j.envint.2010.06.004.

99. Khosravi K, Price GW. 2015. Determination of phthalates in soils and biosolids using accelerated solvent extraction coupled with SPE cleanup and GC-MS quantification. Microchem J 121:205-212. https://doi.org/10 .1016/j.microc.2015.03.013.

100. Newton MS, Arcus VL, Gerth ML, Patrick WM. 2018. Enzyme evolution: innovation is easy, optimization is complicated. Curr Opin Struct Biol 48: 110-116. https://doi.org/10.1016/j.sbi.2017.11.007.

101. Chaguza C. 2020. Bacterial survival: evolve and adapt or perish. Nat Rev Microbiol 18:5-5. https://doi.org/10.1038/s41579-019-0303-5.

102. Cordova ST, Sanford J. 2019. Testing the hypothesis that the nylonase NylB protein arose de novo via a frameshift mutation. ChemRxiv https:// doi.org/10.26434/chemrxiv.7865009.v2.

103. Siddiq MA, Hochberg GK, Thornton JW. 2017. Evolution of protein specificity: insights from ancestral protein reconstruction. Curr Opin Struct Biol 47:113-122. https://doi.org/10.1016/j.sbi.2017.07.003.

104. Muller RJ, Kleeberg I, Deckwer WD. 2001. Biodegradation of polyesters containing aromatic constituents. J Biotechnol 86:87-95. https://doi .org/10.1016/S0168-1656(00)00407-7.

105. Tournier V, Topham CM, Gilles A, David B, Folgoas C, Moya-Leclair E, Kamionka $E$, Desrousseaux $M-L$, Texier $H$, Gavalda $S$, Cot $M$, Guémard $E$, Dalibey M, Nomme J, Cioci G, Barbe S, Chateau M, André I, Duquesne S, Marty A. 2020. An engineered PET depolymerase to break down and recycle plastic bottles. Nature 580:216-219. https://doi.org/10.1038/ s41586-020-2149-4.

106. Austin HP, Allen MD, Donohoe BS, Rorrer NA, Kearns FL, Silveira RL, Pollard BC, Dominick G, Duman R, El Omari K, Mykhaylyk V, Wagner A, Michener WE, Amore A, Skaf MS, Crowley MF, Thorne AW, Johnson CW, Woodcock HL, McGeehan JE, Beckham GT. 2018. Characterization and engineering of a plastic-degrading aromatic polyesterase. Proc Natl Acad Sci U S A 115: E4350-E4357. https://doi.org/10.1073/pnas.1718804115.

107. Fu L, Niu B, Zhu Z, Wu S, Li W. 2012. CD-HIT: accelerated for clustering the next-generation sequencing data. Bioinformatics 28:3150-3152. https://doi.org/10.1093/bioinformatics/bts565.

108. Li W, Godzik A. 2006. Cd-hit: a fast program for clustering and comparing large sets of protein or nucleotide sequences. Bioinformatics 22: 1658-1659. https://doi.org/10.1093/bioinformatics/btl158.

109. Altschul SF, Gish W, Miller W, Myers EW, Lipman DJ. 1990. Basic local alignment search tool. J Mol Biol 215:403-410. https://doi.org/10.1016/ S0022-2836(05)80360-2.

110. Eddy SR. 1998. Profile hidden Markov models. Bioinformatics 14: 755-763. https://doi.org/10.1093/bioinformatics/14.9.755.

111. Li D, Liu C-M, Luo R, Sadakane K, Lam T-W. 2015. MEGAHIT: an ultra-fast single-node solution for large and complex metagenomics assembly via succinct de Bruijn graph. Bioinformatics 31:1674-1676. https://doi.org/ 10.1093/bioinformatics/btv033.

112. Bray NL, Pimentel H, Melsted P, Pachter L. 2016. Near-optimal probabilistic RNA-seq quantification. Nat Biotechnol 34:525-527. https://doi.org/ 10.1038/nbt.3519. 
113. Alneberg J, Bjarnason BS, de Bruijn I, Schirmer M, Quick J, ljaz UZ, Lahti L, Loman NJ, Andersson AF, Quince C. 2014. Binning metagenomic contigs by coverage and composition. Nat Methods 11:1144-1146. https:// doi.org/10.1038/nmeth.3103.

114. Kang DD, Li F, Kirton E, Thomas A, Egan R, An H, Wang Z. 2019. MetaBAT 2: an adaptive binning algorithm for robust and efficient genome reconstruction from metagenome assemblies. PeerJ 7:e7359. https://doi.org/ 10.7717/peerj.7359.

115. Wu Y-W, Simmons BA, Singer SW. 2016. MaxBin 2.0: an automated binning algorithm to recover genomes from multiple metagenomic datasets. Bioinformatics 32:605-607. https://doi.org/10.1093/bioinformatics/ btv638.

116. Uritskiy GV, DiRuggiero J, Taylor J. 2018. MetaWRAP_-a flexible pipeline for genome-resolved metagenomic data analysis. Microbiome 6:158. https://doi.org/10.1186/s40168-018-0541-1.

117. Zorrilla F, Buric F, Patil KR, Zelezniak A. 6 October 2021. metaGEM: reconstruction of genome scale metabolic models directly from metagenomes. Nucleic Acids Res https://doi.org/10.1093/nar/gkab815.
118. Pedregosa F, Varoquaux G, Gramfort A, Michel V, Thirion B, Grisel O, Blondel M. 2011. Scikit-learn: machine learning in Python. J Machine Learning Res 12:2825-2830.

119. Virtanen P, Gommers R, Oliphant TE, Haberland M, Reddy T, Cournapeau D, Burovski E, Peterson P, Weckesser W, Bright J, van der Walt SJ, Brett M, Wilson J, Millman KJ, Mayorov N, Nelson ARJ, Jones E, Kern R, Larson E, Carey CJ, Polat I, Feng Y, Moore EW, VanderPlas J, Laxalde D, Perktold J, Cimrman R, Henriksen I, Quintero EA, Harris CR, Archibald AM, Ribeiro $\mathrm{AH}$, Pedregosa F, van Mulbregt P, SciPy 1.0 Contributors. 2020. SciPy 1.0: fundamental algorithms for scientific computing in Python. Nat Methods 17:261-272. https://doi.org/10.1038/s41592-019-0686-2.

120. Box GEP, Cox DR. 1964. An analysis of transformations. J R Stat Soc Ser B Stat Methodol 26:211-243. https://doi.org/10.1111/j.2517-6161.1964.tb00553.x.

121. Köster J, Rahmann S. 2012. Snakemake-a scalable bioinformatics workflow engine. Bioinformatics 28:2520-2522. https://doi.org/10 .1093/bioinformatics/bts480.

122. Siegel AF. 1982. Robust regression using repeated medians. Biometrika 69:242-244. https://doi.org/10.1093/biomet/69.1.242. 